\title{
LIFE EXPERIENCES, RESPONSE STYLES AND MENTAL HEALTH AMONG MOTHERS AND CHILDREN IN BEIRUT, LEBANON
}

\author{
Jennifer W. Bryce, ${ }^{1}$ Neff Walker, ${ }^{2}$ Francoise GhorayeB ${ }^{3}$ and Mayada Kanj ${ }^{4}$ \\ ${ }^{1}$ School of Public Health, University of Michigan, ${ }^{2}$ Department of Psychology and the Cognitive Science \\ and Machine Intelligence Laboratory, University of Michigan, Ann Arbor, MI 48106. U.S.A.. \\ ${ }^{3}$ Department of Sociology, American University of Beirut and "Faculty of Health Sciences. American \\ University of Beirut, Beirut, Lebanon
}

\begin{abstract}
A sample of 152 women living in Beirut, Lebanon was studied to determine the relationship between life experiences, mothers' depression, and children's health and behavior. Measures of the perceived negative impact of both war and nonwar related events, measures of available social support, sociodemographic variables, coping or response strategies and displacement were used to predict mothers' depressive symptomatology and their children's health.

The level of perceived negative impact of war-related events was found to be strongly associated with higher levels of depressive symptomatology among mothers. More surprising was the relative importance of experiences unrelated to the war in predicting higher levels of depressive symptoms. Among the most noteworthy of the findings was the association between the use of an emotional response style and the measure of psychological dysfunction. Finally, the level of a mother's depressive symptomatology was found to be the best predictor of her child's reported morbidity, with higher levels of symptoms associated with higher levels of morbidity.
\end{abstract}

Key words -war, depression, child behavior, life experiences

\section{INTRODUCTION}

Few previous attempts have been made to document the health and psychological outcomes of war for civilian populations. One recent survey has documented signs of psychological distress among civilians in Lebanon [1], and exposure to armed conflict has been found to lead to prolonged emotional disturbance in Vietnam [2]. Heightened blood pressure has also been documented among pregnant women in Israel who were exposed to combat situations [3]. Migration and displacement, both of which are widespread in areas of political unrest, have also been associated with symptoms of depression [4,5]. Children were found to have heightened death rates during the 1971 civil war in Bangladesh [6], and there is some evidence of the negative impact of war on children in Northern Ireland [7]. While much remains to be learned, existing evidence consistently points to a negative relationship between armed conflict and the health and psychological functioning of both children and adult civilians. Previous research on the effects of violence has tended to limit the independent variables under investigation to discrete war-related events or broader measures of exposure to war, with little attention to the combined effects of violence and more normative experiences common to civilians in peaceful settings. The purpose of the current study was to increase the knowledge base about the impact of war on a specific group of Beirut residents-young children and their mothers. The focus on the psychological health of mothers reflects their potential role as mediators between the external environment and the health and psychological functioning of their young children. Efforts were made to place war events in their broader societal context.
An endemic war has been raging in Lebanon for 12 years. In the capital city of Beirut, this period has been characterized by intermittent and unpredictable violence, including street fighting with machine guns and small artillary, and larger battles which include bombardment, massive displacement of families, and disruptions in public services. This civil unrest has been accompanied by a deterioration of the national economy. In 1982, $51 \%$ of a sample of families with children in West Beirut reported that they had recently experienced a loss of income [8], and schools and institutions serving children have suffered numerous closures and forced reductions in their curricula and services $[9,10]$. Recent population and health studies in Lebanon have documented the deterioration of environmental conditions at the community level [11]. The experience of war combines elements which have been suggested in previous research to lead to severe stress: war events are often uncontrollable and to some degree unexpected, they are likely to continue over long periods of time, and they are life-threatening [12]. Life in Beirut in the recent past reflects all of these characteristics.

The study reported here was designed to investigate the relationship between household characteristics, mothers' experiences and responses, and both the psychological functioning of mothers and the behaviors and health of their children. Exposure to war events was the primary variable under investigation, and was assessed using a checklist of experiences developed through qualitative interviews with mothers of young children in Beirut. In addition to the sheer quantity of experiences, the mother's perception of its negative effect on the family was investigated. Previous research suggests that per- 
ceived negative impact is a more powerful predictor of health and psychological outcomes than is the number of events [13]. The ways in which mothers respond to events were also given particular attention. While the literature on the role of coping strategies and styles in the relationship between health and stress is diverse, certainly the broad pattern of an individual's responses to life events must be taken into account. In this study, mothers' response styles were assessed through the use of a checklist developed through qualitative research with a sample of Beirut mothers [14].

The study was designed to take into account not only war events and mothers' responses to them, but a broad array of other factors which may play a role in the determination of child health in developing countries [15]. These include: (1) family and household characteristics, including income, education, environmental characteristics, and for children, aspects of pre- and postnatal care; (2) residential relocation, both war-related (displacement) and elective: (3) life events other than those which are directly related to the war, including deaths, illnesses, or those related to family relationships, children's performance in school, and levels of financial or personal resources; and (4) the characteristics of the family's social network. Given the absence of a comparison group in Lebanon which has not been exposed to war, it was necessary to assess the impact of war in the context of other aspects of the respondents' daily lives.

\section{METHODS}

The study of the impact of war is fraught with measurement and logistical difficulties. Not least among these is the lack of reliable descriptive information on the circumstances of daily life in areas of armed conflict and culturally appropriate and normed instruments. This study was based upon an earlier, qualitative study designed to provide valid descriptions of the daily lives of women and young children living in West Beirut. A brief description of the qualitative research is provided as those data were used to construct several of the measures in this study.

\section{Qualitative interviews}

Between December 1984 and May 1985, qualitative interviews were carried out with 62 women who had at least one of their children under age 15 currently living with them. The mothers were contacted through two health centers-one located in the central business district of West Beirut, and the other in a Palestinian refugee camp in the southern suburbs of the city. Both centers serve primarily low income families. Interviews were conducted in Arabic in the womens" homes by two graduate students at the American University of Beirut. After the collection of basic demographic information, the interview was unstructured and each mother was asked to describe her experiences since the time of her marriage. For each event mentioned, the interviewer probed for the full details of the circumstances surrounding the event and the mother's response to it. The event-response pairs were abstracted from the inter- views onto specially prepared coding sheets. The abstraction process was complex. as the narratives often involved strings of event-response pairs in which the response to one event became the event in the next. The difficulties inherent in breaking down the stream of experience into units of analysis have been discussed elsewhere [16]. The reliability of the unitizing process was increased by having two independent judges initially abstract $20 \%$ of the interview transcripts, and then compare their abstractions and work with a third judge to resolve any differences. The events and responses were analyzed separately and used as the basis for the more structured life experience and response style instruments which were used in the research reported here. A full description of the methods for the qualitative portion of the research [17], as well as a selection of full-length interviews [14], are available elsewhere.

\section{Sample}

A nonrandom sample of 152 children and their mothers was drawn from three pre-school programs in West Beirut. Schools were selected for participation on the basis of: (1) geographic location and accessibility within West Beirut; (2) diversity of income and religious backgrounds present in the school; and (3) size, with a preference for larger schools. All three schools were in areas which had been exposed to heavy fighting over the 2 years previous to data collection. One was located close to the dividing line between East and West Beirut; one in an area populated primarily by Palestinians in the southern suburbs of the city; and one in the central business district of West Beirut. Within schools, all classrooms with pupils between the ages of 5 and 7 were included in the study. All children in each classroom were screened for height, weight, and arm circumference, and their mothers were then contacted and asked to participate in the research. The sample reflects all mothers who agreed to participate and for whom interviews were able to be completed.

\section{Procedures}

The survey questionnaire was administered in Arabic by female graduate students in the Faculty of Health Sciences at the American University of Beirut between November 1985 and July 1986. Interviewers received extensive training including the preparation and review of audiorecorded practice interviews. Interviews were conducted at a site selected by the respondents. The majority of mothers $(82.2 \%)$ were interviewed at home, and the remainder were interviewed either in the school $(14.5 \%)$ or in another setting of their choice $(3.3 \%)$.

\section{Outcome measures}

Depressive symptomatology among mothers. An Arabic version of the Beck's Depression Inventory [18] was used as the basis for this dependent variable. This instrument has been used previously in Lebanon [19], and results in a single overall score. It is normally composed of 21 items, but for the current study two items (those relating to suicide and sexual behavior) were removed in response to a suggestion by a panel convened to review the cultural appropriateness of the research instrument. The final 
instrument includes 19 items and a possible range in scores from 0 to 57 .

Child health and behavior. The indices of child health in the original research design included height, weight, and arm circumference measurements taken by trained research assistants in the child's classroom. Previous assessments in Lebanon have found children living with their families to fall within the normal range of physical development, as malnutrition has not been a problem facing the general population [20]. When the physical measures in the current study were adjusted for age, they showed limited variability and were not significantly correlated with any of the predictor variables under investigation. They were therefore excluded from the remainder of the analysis and are not reported on in this paper. Remaining indices include a summary measure reflecting mothers' reports of the number of times a child was ill in the month previous to the interview and the number of hospitalizations in the previous year. Different recall periods were used for illnesses and hospitalizations because previous research in Lebanon [21] and other countries (e.g. Ref. [20]) suggests that accuracy of recall of morbidity varies both with the frequency of events and their severity. While hospitalizations contribute relatively little to the summary measure, the combination of the two types of events was thought to provide a better measure of child morbidity than either taken alone. Mothers were also asked to respond to a 19 item scale assessing behaviors of young children which was adapted from the Richmann's Checklist for Child Behavior [22]. While there are no normative data for this instrument in Lebanon, it is currently being used in a study of Palestinian children in refugee camps in Jordan. The measure was chosen because it was the best available measure of child behavior and could provide a basis for future comparisons with similar populations. The scale results in an overall score between 0 and 57 with higher scores reflecting greater disturbance in a child's behavior.

\section{Predictor variables}

There were 22 primary predictor variables used in the current analysis, grouped into five content categories: (1) sociodemographic and environmental; (2) displacement and residential relocation; (3) life experiences: (4) mothers' response styles; and (5) social support. The specific predictor variables have been numbered throughout the report to improve clarity.

Sociodemographic and environmental measures. Sociodemographic variables included the educational level of the mother (variable 1.1) and the mean monthly income per permanent household resident (variable 1.2). Two summary measures were constructed to evaluate the potential impact of the environment on the physical health of the child. The first assessed a selection of threats to child health which may occur during pregnancy and birth (variable 1.3). A score of one was awarded for each of the following: (1) delivery outside the hospital; (2) low birth weight; (3) a breast-feeding period of less than 6 months: and (4) a mother who smoked during pregnancy. The second summary measure assessed potential environmental risks to child health (variable
1.4). Again a score of one was awarded for each of the following: (1) crowding in the household (defined as the ratio of residents to rooms greater than $1.5: 1.0)$; (2) no running water in the household; (3) no toilet in the household; (4) no reportedly consistent practice of disinfecting household drinking water; and (5) no generator available to ensure the presence of water and refrigeration during the extended periods when public electricity is not available. For both measures, higher scores reflect a greater number of threats to child health.

Displacement and residential relocation. Displacement was defined as the forced abandonment of the home for a period of at least one night due to war events or fear of war events. A history of displacement experiences was collected for the period since $1975-76$ or the woman's marriage, whichever was most recent. Three variables reflecting housing and residential relocation have been included in the analysis: (1) the number of temporary displacements (variable 2.1 ); (2) the total length of time (in weeks) the family was displaced (variable 2.2 ); and (3) the number of times the family changed residences (variable 2.3 ). The latter variable reflects relocation either by necessity or by force.

Life experiences. A life experiences checklist was constructed based on those events which had been reported five times or more by respondents in the qualitative portion of the research. The instrument includes both items which are directly related to the war (e.g. fighting in the neighborhood, family member kidnapped, detention by militia) and those which were only peripherally related to the war or independent of it (e.g. becoming pregnant, children having problems at school). The language used by the mothers in the qualitative study to refer to each event was retained whenever possible. Mothers were presented with each of 40 situations or occurrences and asked to indicate how many times they had experienced it in the 6 months prior to the interview. For each item they reported they had experienced, they were asked to rate the degree of negative impact the event had on the family on a five-point scale by pointing to a color chart which ranged from block for 'severe negative impact' through three shades of gray to white for 'no negative impact'.

Six summary variables have been created based on the life experiences checklist. The first two variables refer to the number of different experiences reported by the mother, regardless of the number of times each was experienced. Variable 3.1 reflects the total number of different experiences, and variable 3.2 the total number of different experiences directly attributable to the war. The third and fourth variables refiect the sum of all experiences, including repetitions, both for all events (variable 3.3) and for the subset of war-related events (variable 3.4 ). The final two variables reflect the sum of negative impact ratings of events (including repetitions) as perceived by the mother. Again there are two separate indices, one reflecting the total perceived negative impact of all events (variable 3.5) and one the total negative impact for war-related events only (variable 3.6).

Response styles. A second checklist was constructed to assess the ways in which mothers respond when faced with problems. Again the 40 checklist items and 
their wording are based on the responses reported in the 62 qualitative interviews, and represent a broad range of possible responses. Each item was read by the interviewer, and respondents were asked to indicate on a five-point scale (ranging from never to always) how often they respond in a particular way when faced with a problem.

Checklist data on mothers' responses were subjected to factor analysis to determine whether there were unifying dimensions underlying the individual checklist items. Six subscales were identified, and the mother's average rating on items within a subscale has been used as an independent variable in the current analysis. Two items, 'I smoke more than usual' and 'I try to find someone or something to blame it on' did not load heavily on any of the six subscales, and were therefore dropped from the analysis. Variable 4.1 reflects mothers' use of a family oriented response style. Mothers who score high on this scale report that when faced with a problem they talk to their husbands or other family members or go to them for help, they pay a visit to their family, or that the mere presence of family members reduces the impact of a problem. Items in the emotion oriented response scale (variable 4.2 ) include hitting one's children, becoming nervous and worried, screaming, yelling, and becoming angry, becoming sad or hopeless, and trying to be alone. Mothers who score high on this scale are less likely to seek help or take action directed at the problem, and are more likely to respond through their emotions. The cognitively oriented response subscale is composed of responses which are characterized by mental effort to reduce the impact of the problem (variable 4.3). These include trying to find an explanation for what happened, thinking about the eventual outcome of the problem, focusing on the future, and trying to find a solution for the problem. Variable 4.4 reflects a mother's tendency to respond in a socially oriented waylooking outside the family circle for relief and assistance. Items in this category include talking to friends or going to them for help, and trying to have more fun with friends. The fifth response style is diversion or denial (variable 4.5). Mothers who score high on this scale report that when faced with a problem they are likely to listen to the radio or watch television, to try and think about something else or forget about it, or to keep busy and try to ignore it. The final response style includes three items which indicate acceptance of the problem and a sense of powerlessness (variable 4.6). Items in this subscale include being patient, doing nothing, and accepting that what happened is God's will. Also in this category are reports that one's response is simply to cry. The number of items within each subscale varied from three to seven. For the purpose of analysis and presentation and analysis of means, the average rating for items within a subscale was used rather than a total score.

Social support. This measure was created to assess the characteristics of the respondents' social networks, and their perceived adequacy. Mothers were asked to provide first names for each person they reported they would turn to in each of six specific areas of need in their daily lives (financial, emotional, child care, fun, and safety). They were then asked to describe each individual (age, sex, relationship to the respondent), and the number of times they had needed, asked for, and obtained help over the previous month. Finally, mothers were asked whether or not they were satisfied with the level of help they received in each of the six categories. Three summary measures based on these data were used in this analysis. They include: (1) the size of the social network, measured by the number of different individuals reported across all six categories (variable $5.1)$; (2) the level of perceived need for assistance from the social network, calculated as the number of times in the past month the respondent reports that she needed help across each of the six areas (variable 5.2); and (3) the overall level of dissatisfaction with the network, based on a score of ' 1 ' for each of the six categories in which she felt she had all the help she needed, and ' 2 ' in those categories in which she felt she did not have enough assistance (variable 5.3). Higher scores on variable 5.3 indicate greater dissatisfaction with network support.

\section{RESULTS}

Mothers' scores on the Becks Depression Inventory ranged from 0 to 33 , with a mean score of 11.31 (SD 7.49). The sum of children's illnesses and hospitalizations ranged from 0 to 3 , with a mean of 0.75 (SD 0.72). Mothers' ratings of their children on the Child Behavior Rating Scale ranged from 0 to 57 , with a mean of 27.72 (SD 8.91).

Descriptive statistics for the predictor variables have been presented in Table 1 , and a full correlation matrix for the predictor and outcome variables is available in Table 2. Individual significance levels of the correlation coefficients reported have not been adjusted for the number of correlations performed. Interpretations of the relationships between variables therefore must be made with care. Emphasis should be placed on patterns of results rather than individual correlation coefficients. The categories of independent variables will be discussed at the bivariate level, followed by a presentation of the results of the multivariate analyses.

\section{Displacement and residential relocation}

Three out of four of the sample families reported that they had been displaced from their homes for a period of at least one night since 1975-76 or the time of their marriage, and $23 \%$ had been displaced in the 6 months previous to the interview. The number of times a family had relocated was positively correlated with income levels (see Table 2), perhaps reflecting the ability of families with more resources to relocate as needed to improve their living conditions or security. No other significant correlations were found between the indicators of displacement and the other selected socioeconomic indicators

\section{Mothers' experiences in wartime West Beirut}

The frequency with which specific life events were experienced by mothers in the 6 months prior to the interview and mean perceived negative impact of each event are presented in Table 3 . The five events experienced by the greatest proportion of this sample of Beirut women were all directly related to the 
Table 1. Independent variables and descriptive statistics

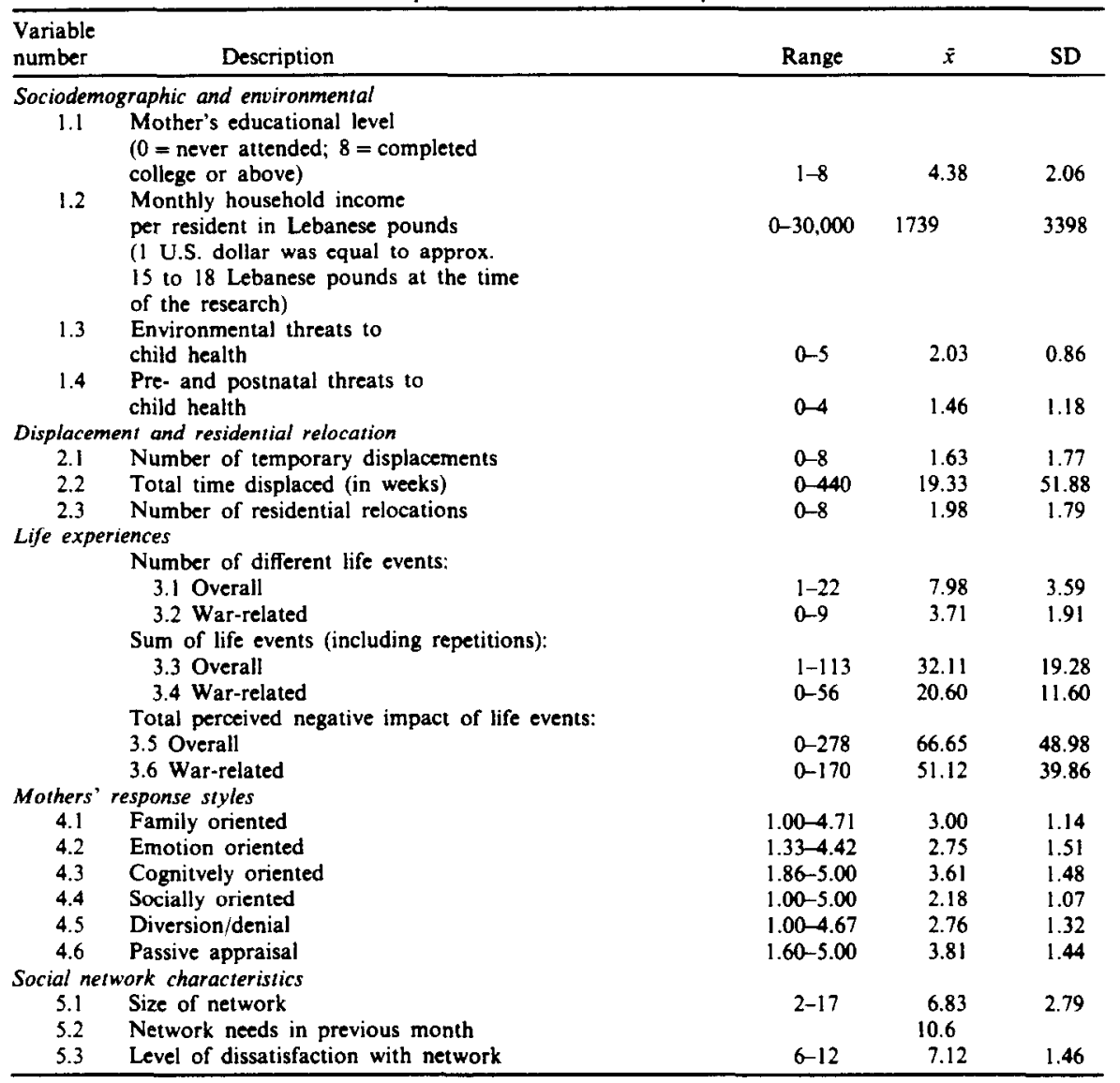

Lebanese war. Several nonwar experiences, however, were rated as having extremely high negative impact. The death of a member of one's nuclear family has a surprisingly low level of negative impact. Upon further investigation it was discovered that this low level of overall impact was due to the effect of one rating (out of a total of seven) reflecting the welcome death of a respondent's mother after a long illness.

A series of Pearson correlations was performed to investigate differentials in life experience scores based on the socioeconomic characteristics of the households. It was found that mothers with low levels of education are significantly more likely to report greater numbers and a greater variety of life experiences, and significantly greater negative impact of those experiences, than are mothers with more education. This relationship holds for the sum of all war-related experiences, but not for the number of different war-related experiences. The same pattern of relationships was found with respect to income levels: mothers in households with low income levels are significantly more likely to experience negative life experiences, and to perceive those experiences to have a greater negative impact, than are mothers in households with relatively higher income levels.

\section{Mothers' response styles}

The correlation coefficients for the response subscales and the socioeconomic variables (educational level of mother and household income per resident) are available in Table 2 . The results indicate that the use of some types of responses is highly correlated with income or education, while for others there is no statistical relationship. Emotion oriented responses and passive appraisal are used significantly more often by mothers with lower levels of education. Reported use of denial and diversion is also negatively correlated with both education and income. Also evident at the bivariate level is a strong positive relationship between emotional or passive responses and the total number of life events experienced and their variety.

Two regression analyses were run to establish the relative importance of life experiences and socioeconomic indicators in predicting mothers' use of emotional and passive response styles. As presented in Table 4, the results indicate that the educational level of the mother is the most powerful predictor of the use of both emotional and passive response styles, followed by the perceived negative impact of events and the total number of life experiences for emotional and passive styles, respectively.

\section{Social networks}

Returning to Table 1, mothers reported a mean of seven individuals in their social networks across the six content areas in which they might need assistance. The size of the social network was positively 


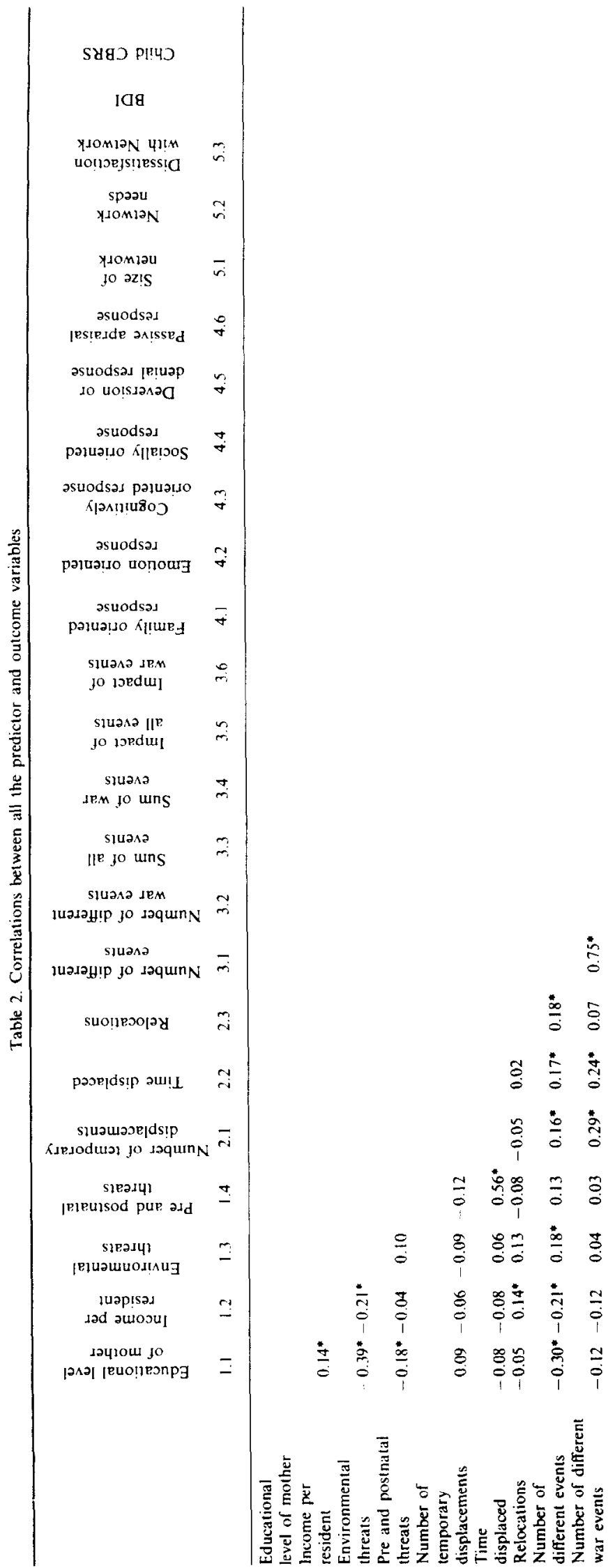




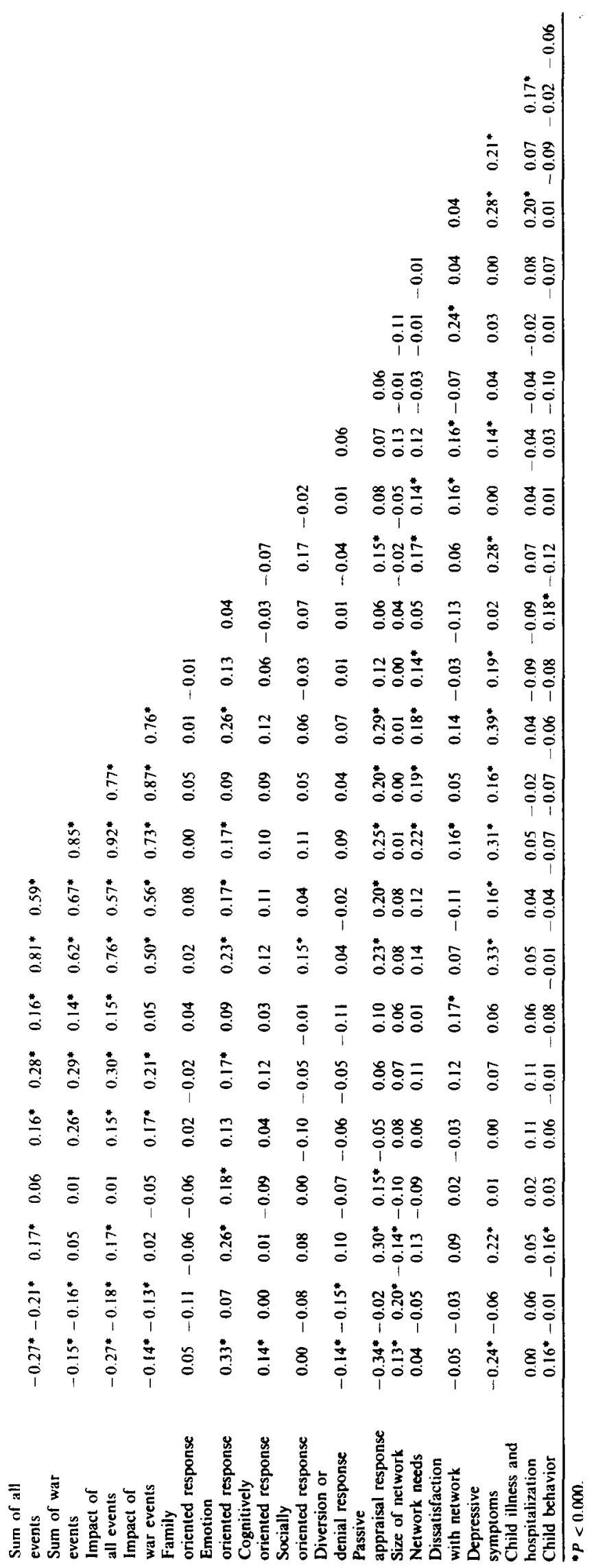


Table 3. $\%$ of women reporting lite experiences in 6 months prior to interview

\begin{tabular}{lccc}
\hline & No. & $\%$ & Mean impact \\
\hline Being without electricity & 128 & 84.2 & 1.80 \\
Fighting in the neighborhood & 112 & 73.7 & 2.42 \\
Not able to see relatives due to war & 92 & 60.5 & 2.01 \\
Family member frightened or scared & 88 & 57.9 & 2.31 \\
Not having a safe place to go & 71 & 46.7 & 2.43 \\
Unable to go out due to situation & 70 & 46.1 & 1.87 \\
Not having enough money for the family & 70 & 46.1 & 2.24 \\
Not having enough room in the house & 65 & 42.8 & 1.94 \\
Children having problems at school & 47 & 30.9 & 2.00 \\
Being without water & 46 & 30.3 & 1.45 \\
Having to go to a shelter & 46 & 30.3 & 2.50 \\
Death of a nonnuclear family member & 41 & 27.0 & 1.90 \\
Illness in nuclear family & 37 & 24.3 & 2.49 \\
Having other displaced people in the home & 37 & 24.3 & 0.92 \\
Forced to leave home (displaced) & 35 & 23.0 & 2.22 \\
Home or belongings damaged or destroyed & 33 & 21.7 & 2.06 \\
Birth of a child & 26 & 17.1 & 0.85 \\
Personal problems with family members & 25 & 16.4 & 2.31 \\
Personal problens with husband & 18 & 11.8 & 2.50 \\
Becoming pregnant & 17 & 11.2 & 0.59 \\
Not having enough food for the family & 15 & 9.9 & 1.80 \\
Husband or self losing job & 15 & 9.9 & 2.1 .7 \\
Nonnuclear family member ill & 14 & 9.2 & 2.43 \\
Death of a close friend & 14 & 9.2 & 2.07 \\
Taking on extra work to make ends meet & 13 & 8.5 & 0.19 \\
Family member kidnapped & 9 & 6.0 & 2.56 \\
Family member wounded & 8 & 5.3 & 2.13 \\
Death or nuclear family member & 7 & 4.6 & 2.11 \\
Detention by militia & 3 & 2.0 & 2.00 \\
\hline
\end{tabular}

Table 4. Results of multiple regression analyses with the life experience measures. mother's educational level, and monthly income per resident as predictor variables and two response styles as outcome variables

\begin{tabular}{clcccc}
\hline Step & \multicolumn{1}{c}{ Variable name } & Multiple $R$ & $R^{2}$ & $F$ & Sig $F$ \\
\hline \multicolumn{7}{c}{$\begin{array}{c}\text { Emotional response style } \\
1\end{array}$} & Mother's educational level & 0.313 & 0.098 & 12.75 & 0.001 \\
2 & Total impact rating & 0.365 & 0.133 & 8.90 & 0.000 \\
3 & Sum of life experience & 0.427 & 0.182 & 8.54 & 0.000 \\
\multicolumn{7}{c}{ Passite appraisal response style } \\
1 & Mother's educational level & 0.352 & 0.124 & 16.59 & 0.00 \\
2 & Total impact rating & 0.429 & 0.184 & 13.05 & 0.000 \\
\hline
\end{tabular}

correlated with education and income levels (see Table 2), but neither of the other two network measures were associated with the socioeconomic indicators. Levels of satisfaction with the support provided by the social network decreased as the number of residential relocations increased.

\section{Predictors of depressive symptomatology}

A series of Pearson correlations was run for each of the independent variables under investigation and mothers' scores on the Beck's Depression Inventory (BDI). Ten of the 22 variables were found to be significantly associated with mothers' levels of depressive symptomatology, and the resulting coefficients are presented in Table 2.
A stepwise multiple regression was then performed using the full set of predictor variables, and the results are presented in Table 5 . The mean impact rating for all life experiences entered the equation first, and explained $15.8 \%$ of the variance in mothers' scores of depressive symptomatology. The second variable entered into the equation was the sum of all war experiences, explaining a further $7.5 \%$ of the variance. The final variable to explain a significant amount of variation at the $P<0.05$ level was the extent to which the mother reported an emotional response style. These three variables combined to explain a total of $26.9 \%$ of the variance in the measure of depressive symptomatology.

Table 5. Multiple regression analysis with mother's scores on the depression inventory as the outcome variable and mother's educational level, monthly income per resident, two indicators of threats to child health, the six measures of life experiences, three measures of displacement, scores on six response subscales, and three social network measures as predictor variables

\begin{tabular}{clcccc}
\hline Step & \multicolumn{1}{c}{ Variable name } & Multiple $R$ & $R^{2}$ & $F$ & Sig $F$ \\
\hline 1 & Total impact rating & 0.397 & 0.158 & 17.25 & 0.000 \\
2 & Sum of war-related experiences & 0.483 & 0.233 & 13.82 & 0.000 \\
3 & Emotional response style & 0.519 & 0.269 & 11.03 & 0.000 \\
\hline
\end{tabular}




\section{Predictors of child morbidity and behavior}

At the bivariate level, the measure of child illnesses and hospitalizations was found to be positively correlated with the total number of needs the mother reported over the last month with respect to her social network, as well as the level of the mother's depressive symptomatology. The behavior rating scale showed a different pattern of results, and was positively associated with the mother's educational level and the extent to which she reported turning to family members with problems, and negatively correlated with the number of environmental threats to child health.

Path analysis was then used to develop and test a preliminary processual model of the predictors of child morbidity and behavior among this Beirut sample. Using the results of the earlier analysis, a conceptual model was developed to predict child illnesses and hospitalizations (Fig. 1). The results suggest that mothers' levels of depressive symptomatology are the most important predictor of reports of child morbidity. While there are significant relationships between the intermediary variables at the bivariate level, the only measure in the model which is related to child illness is the mother's score on the BDI.

The same conceptual model and predictor variables were then used to predict the child's score on the Behavior Rating Scale. As can be seen in Fig. 2, the beta coefficients are similar to the earlier model, except for the strength of the pathways which lead directly to the dependent variable. As in the pre- diction of child morbidity, only one variable was significantly related to children's behavior, although in this case it was the number of environmental threats in the home rather than the mother's score on the measure of depressive symptomatology.

The findings with respect to the determinants of child morbidity and behavior must be treated with caution, because both outcome measures are imperfect. Reports of child illness by the mother may be biased by memory, by the mother's ability to recognize symptoms and seek medical attention, and by social desirability bias. The child behavior rating scale is only a gross measure of some of the behavioral difficulties commonly experienced by young children, and should not be confused with a clinically valid measure of child mental health. Despite these limitations, the finding of the importance of mothers' mental health in predicting child morbidity is robust, and merits further attention.

Among the most important of the results presented here is the evidence concerning the predictors of depression among mothers living under war conditions. As suggested in earlier research on stressful life events [13], the perceived impact of experiences was found to be a more powerful predictor of mental disturbance than were the more objective measures of the numbers of events, or even exposure to that subset of events which are directly related to the war. While there is a recognized circularity in using perceived negative impact ratings to predict depression, these findings remind us that armed conflict does not take place in a vacuum-the daily lives of civilians in

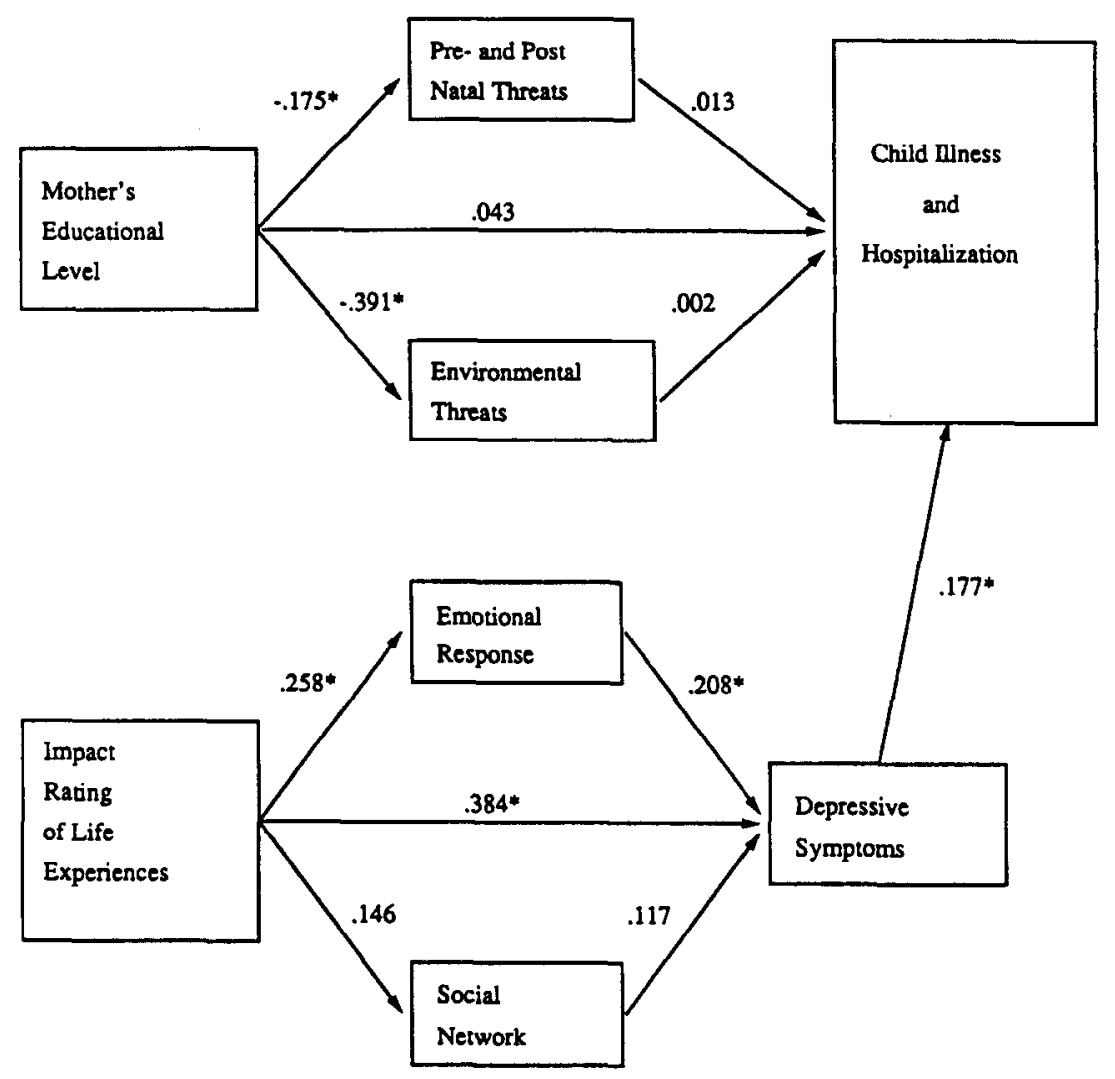

Fig. 1. Path analysis of the predictors of child illness and hospitalization. 


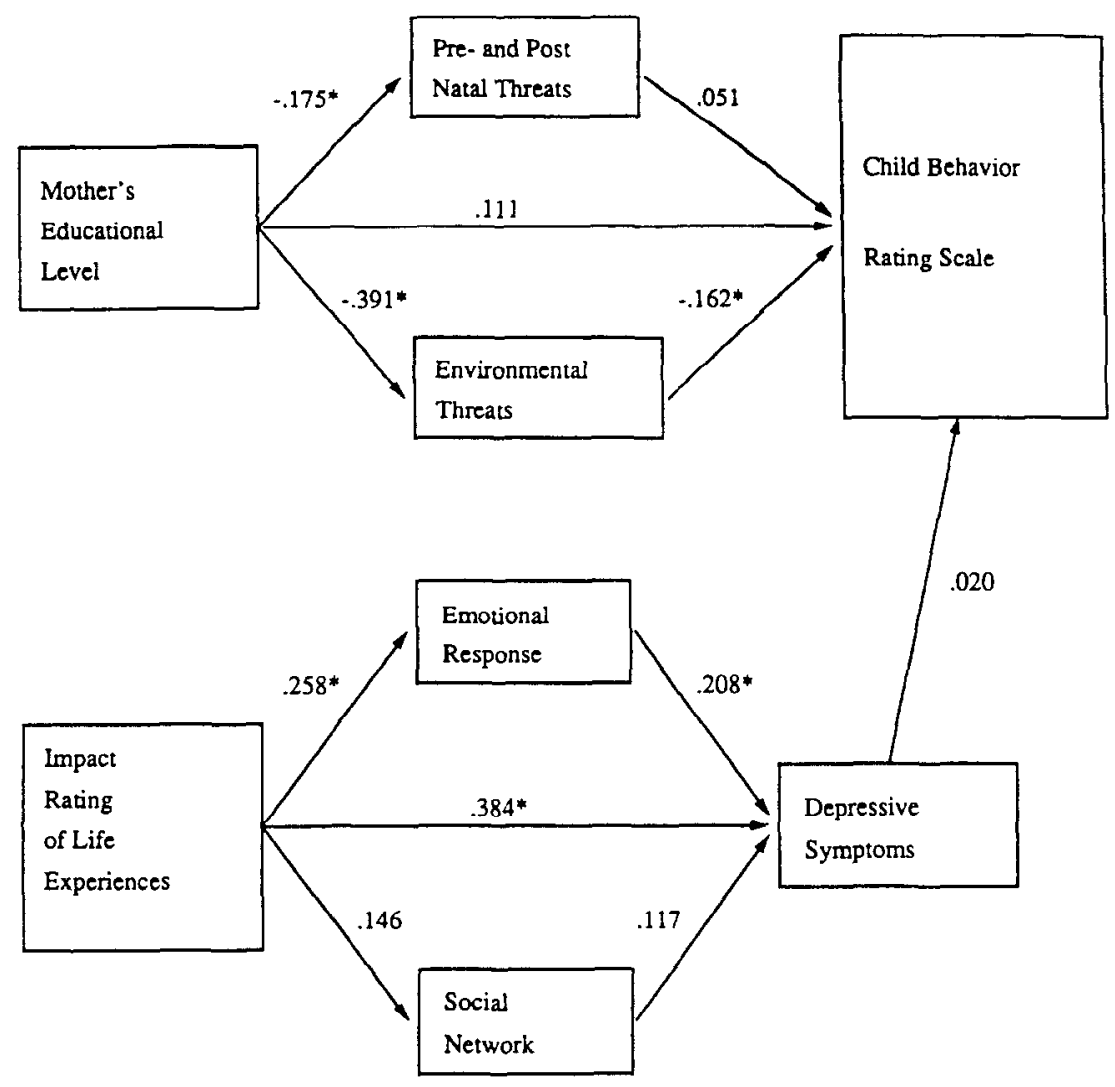

Fig. 2. Path analysis of the predictors of the child behavior rating scale.

war zones are subject to many of the same crises found in more peaceful areas; crises which the stresses of war do not necessarily supplant. Further evidence for the importance of normative events was found during the qualitative portion of this research [14], as well as in other studies of college students in Lebanon [19]. Clearly, research on the impact of violence on health in developing countries should take a broad focus, including normative experiences and the results of societal deterioration in addition to the traditional measures of exposure to war events.

The use of an emotional response style by mothers was also found to have independent power in predicting depressive symptomatology. These results suggest that given circumstances which are perceived by mothers to be equally damaging, and given exposure to an equal number of war events, mothers who respond to problems emotionally, by getting upset, hitting their children, yelling, or losing hope are more depressed than are mothers who do not respond in this way. While no final statement can be made about the direction of causation (i.e. Do mothers who respond emotionally become more depressed, or do depressed mothers respond more emotionally?), the findings suggest that response styles are an important consideration in our understanding of human behavior under war conditions.

These results concerning the relationship between response styles and depression take on additional importance in light of the finding that there are systematic variations in the use of particular responses across socioeconomic groups. Patterns of response among mothers were found to be associated with their level of education, with the number of problems they face and their assessment of the negative effects of these problems on their lives, and with the number of times the family has changed residence. Evidence has been presented which suggests that response styles which are emotional or which include a sense of fatalism are more often found among women with low levels of education, while mothers with more education tend to try to understand and solve their problems.

Mothers and children at the lower end of the socioeconomic scale are suffering disproportionately from the effects of the Lebanese war. They are significantly morc likely than their more affluent peers to experience all kinds of life experiences, including war-related events, and to rate those events as have a negative impact on their lives.

\section{CONCLUSION}

In West Beirut, mothers who perceived the events in their lives as affecting them negatively, mothers who were exposed to more war-related events, and mothers who reported a tendency to respond to these events in an emotional manner, were found to have the highest levels of depressive symptomatology. These symptoms of depression among mothers were then associated with increased morbidity among their 5-7-year-old children. Further research can improve our understanding of this process by utilizing more sensitive measures of child health 
and psychological functioning, and attempting to document the direction of causation.

While neither this study nor other recent research has found a sharp decline in the overall health of the people of Beirut (cf. Refs [11, 23]), what can be drawn from this work is the relative importance of the long term and more indirect effects of war on a population. War-related events do not occur in isolation; rather they occur in the context of everyday life and serve to compound difficulties and gradually overload the resources of individuals and their society. As the length of the war increases, one can expect both individuals and society to have fewer and fewer resources to draw upon. The importance of the long term and perhaps less obvious (when compared to massacres or bombardments) factors may be even greater in other countries which did not have the same high level of medical and public health development as did Lebanon prior to the war. While the importance of societal conditions may seem sclf-cvident to the academic community, it is not generally reflected in many relief efforts. In the past there has been a tendency to provide assistance in response to major acts of violence, and fewer efforts to alleviate the distress caused by long-term societal deterioration.

All research on the consequences of war should also be directed toward its cessation. Documentation of the deleterious effects of political unrest for civilian populations should be relentlessly focused on peace initiatives and relief programs. The findings reported here indicate a great need for assistance for resourcepoor mothers of young children in Beirut. At the very least, these women need safe havens from the violence which surrounds them, and a source of hope and support to counter their realistic sense of powerlessness.

Acknowledgements - This research was funded by a grant from UNICEF and carried out at the American University of Beirut, where Dr Bryce and Dr Walker were faculty members during the study period. The authors would also like to express their appreciation for the help and support of Ms Nabila Brier in making this work possible.

\section{REFERENCES}

1. Lockwood L. H., Armenian H., Zurayk H. and Afifi L. A population-based survey of loss and psychological distress during war. Soc. Sci. Med. 23, 269-275, 1986.

2. Murphy H. J. M. War stress and civilian Vietnamese: a study of psychological effects. Acta psychiat. scand. 72, 92-108, 1977.

3. Rofe $Y$. and Goldberg J. Prolonged exposure to a war environment and its effects on the blood pressure of pregnant women. Br. J. Med. Psychol. 56, 305-311, 1981.

4. Shisana O. and Celentano D. Depressive symptomatology among Namibian adolescent refugees. Soc. Sci. Med. 21, 1251-1257, 1985.
5. Vega W. A., Kolody B., Valle R. and Hough R. Depressive symptoms and their correlates among immigrant Mexican women in the United States. Soc. Sci. Med. 22, 645-652, 1984.

6. Curlin G. T., Chen L. C. and Hussain S. B. Demographic crisis: the impact of the Bangladesh civil war (1971) on births in a rural area of Bangladesh. Popul. Stud. 30, 80-105, 1976.

7. Fraser M. Children in Confict. Penguin. London. 1974.

8. Jamal R., Shaya M. and Armenian H. K. Child health under emergency conditions. In Wartime: The State of Children in Lebanon (Edited by Bryce J. W. and Armenian H. K.). American University of Beirut, Beirut, 1986.

9. Bryce J. W., Sha'ar K., Shaya M. and Jamal R. Child care institutions. In In Wartime: The State of Children in Lebanon (Edited by Bryce J. W. and Armenian H. K.). American University of Beirut. Beirut, 1986.

10. Knight C. K. The state of the schools. In In Wartime: The State of Children in Lebanon (Edited by Bryce J. W. and Armenian H. K.). American University of Beirut, Beirut, 1986.

11. Turayk H. C. and Armenian H. K. (Eds) Beirut 1984: A Population and Health Profile. American University of Beirut, Beirut, 1985.

12. Figley C. R. Catastrophes: an overview of family reactions. In Stress and the Family. Vol. II: Coping with Catastrophe (Edited by Figley C. R. and McCubbin H. I.). Brunner/Mazel, New York, 1983.

13. Sarason I. G., Johnson J. H. and Siegel J. M. Assessing the impact of life change: development of the Life Experience Survey. J. consult. clin. Psychol. 46, 632-646, 1978.

14. Bryce J. W. Cries of Children in Lebanon. UNICEF, Beirut, 1986.

15. Mosley W. H. and Chen L. C. (Eds) Child Survival: Strategies for Research. A supplement to Vol. 10 of Popul. Devl. Ret. 1984.

16. Krippendorf F. Content Analysis: An Introduction to its Methodology. Sage, London, 1980.

17. Bryce J., Kanj M., Ghorayeb F. and Walker N. Life experiences among low-income mothers in Beirut. J. Marriage Family. 50, 811-819, 1988.

18. Beck A. T., Ward C. H., Mendelson M., Mock J. and Erbaugh J. An inventory for measuring depression. Archs gen. Psychiat. 4, 561-571, 1961.

19. Walker N., Bryce J. W. and Mukaddam J. A comparison of coping styles among college students in Lebanon. Paper presented at the Regional Meeting of the International Association for Cross-Cultural Psychology, Malmo, Sweden, June 1985.

20. Ayyoub C.. Uthman I. and Najjar M. The physical health of children. In In Wartime: The State of Children in Lebanon (Edited by Bryce J. W. and Armenian H. K.). American University of Beirut, Beirut, 1986.

21. Linder F. E. National health interview surveys: trends in the study of morbidity and mortality. Wld Hlth Org. Publ. Hlth Papers 27, 78-111, 1965.

22. Rädda Barnen (Swedish Save the Children). Protocol under agreement with the United Nations Relief and Works Agency for Palestine Refugees in the Near East for Mental Health Project in Jordan, 1985.

23. Bryce J. W. and Armenian H. K. (Eds) In Wartime: The State of Children in Lebanon. American University of Beirut, Beirut, 1986. 